\title{
Hydraulic \& Design Parameters in Full-Scale Constructed Wetland \& Treatment Units: Six Case Studies
}

$\underline{\text { Vasiliki G. Ioannidou }}^{1}$, Jonathan M. Pearson²

${ }^{1}$ School of Engineering and the Built Environment, Birmingham City University, Curzon Street, Birmingham, B4 7XG, UK

(previously at the University of Warwick, School of Engineering, CV4 7AL, UK)

(vasiliki.ioannidou@bcu.ac.uk; v.ioannidou@warwick.ac.uk; tel: 0044 (0) 7597516115; ORCID: 0000-0003-3083-9723)

${ }^{2}$ School of Engineering, University of Warwick, Coventry, CV4 7AL, UK

(j.m.pearson@warwick.ac.uk)

\begin{abstract}
The efficiency of pond and constructed wetland $(\mathrm{CW})$ treatment systems, is influenced by the internal hydrodynamics and mixing interactions between water and aquatic vegetation. In order to contribute to current knowledge of how emergent real vegetation affects solute mixing, and on what the shape and size effects are on the mixing characteristics, an understanding and quantification of those physical processes and interactions was evaluated.

This paper presents results from tracer tests conducted during 2015-2016 in six full-scale systems in the UK under different flow regimes, operational depths, shapes and sizes, and in-/outlet configurations. The aim is to quantify the hydraulic performance and mixing characteristics of the treatment units, and to investigate the effect of size and shape on the mixing processes. Relative comparison of outlet configuration, inflow conditions, and internal features between the six different treatment units showed variations in residence times of up to a factor of 3. A key outcome of this study, demonstrated that the width is a more important dimension for the efficiency of the unit compared to the depth. Results underlined the importance of investigating hydrodynamics and physics of flow in full-size units to enhance treatment efficiency and predictions of water quality models.
\end{abstract}

Keywords: Constructed Wetlands; Hydrodynamics; Full-Scale; Longitudinal Mixing; Residence Time; Fluorescent Tests

\section{ACKNOWLEDGEMENTS}

The work has been financially supported by the School of Engineering, University of Warwick, through a PhD scholarship for V. Ioannidou. The authors gratefully acknowledge the RSPB Hope Farm staff invaluable support, kind collaboration, and permission to access their wetlands; The Coal Authority staff for their productive collaboration, and access to their facilities in Derbyshire and Yorkshire; the technical support from Ian Baylis in the School of Engineering, University of Warwick. A previous shorter version of the paper has been presented in the $10^{\text {th }}$ World Congress of EWRA'Panta Rei', Athens, Greece, 5-9 July 2017. 


\section{HIGHLIGHTS}

- Even inflow distribution of influent and smooth operational conditions is important to be maintained in the system; disruption of even inflow conditions was found to result into poor solute mixing levels, and into internal recirculations of the contaminant in treatment.

- Bunded outlet configuration can improve significantly the mixing and hydraulic performance of the treatment unit.

- Internal configuration using baffles curtains as retrofit has the potential to enhance significantly the hydraulic performance of the treatment unit.

- The width of the treatment unit was found to be a more relevant dimension to the solute/contaminant mixing characteristics compared to the depth.

\section{LIST OF ACRONYMS}

$\begin{array}{ll}\text { CW } & \text { Constructed Wetland } \\ \text { HRT } & \text { Hydraulic Residence Time } \\ \text { RSPB } & \text { Royal Society of Bird Protection } \\ \text { SW1 } & \text { South Wetland } 1 \\ \text { SW2 } & \text { South Wetland 2 } \\ \text { NW } & \text { North Wetland } \\ \text { A-WMTS } & \text { A-Winning Minewater Treatment Scheme } \\ \text { RTD } & \text { Residence Time Distribution } \\ \text { CSTR } & \text { Completely Stirred Tank Reactor } \\ \text { TIS } & \text { Tank In Series } \\ \text { ERAR } & \text { Environmental Risk Assessment Research } \\ \text { CRD } & \text { Chemical Regulatory Directorate }\end{array}$




\section{INTRODUCTION}

Global water contamination is gaining increasing importance at an international level. Mitigation of water pollution has nowadays become a priority for the environmental management, as water resources become severely contaminated due to various anthropogenic activities. As a consequence, there is an increasing engagement to set and advance regulations and policies internationally to protect drinking water quality (2006/7/EC) (European Commission, 2006), and aquatic ecosystems, as enacted by the EU Water Framework Directive (2000/60/EC) (European Commission, 2000).

Many stakeholders have shown their interest in the increasing contamination of the natural water recipients and drinking water supplies. Environmental managers require information about urban and agricultural runoff pollution to preserve standards; the farming community (i.e. farm advisers, and farmers), various national regulators (i.e. Environment Agency, and Chemical Regulatory Directorate), and modellers need information to conform to the environmental regulations and water quality criteria. Moreover, utility managers use information related to travel time and quality of the treated effluents entering watercourses.

Effective water management is needed in order to alleviate the stresses on water as a resource, which is related to the economic value of water, to human health through access to good quality of drinking water supplies, to degradation of aquatic ecosystems, and to global food markets. Therefore, understanding the spread of contamination in waterways is of high importance. Within the environmental context, it has been observed that ecological engineering resources, as the Sustainable Drainage Systems, are capable of mitigating pollution and of providing water purification (Wu et al, 2013). Integration of natural drainage systems, such as constructed wetlands (CWs), vegetated ponds, swamps, permeable pavements and more, are used to manage flood incidents and to treat contamination in the source (Scholz et al 2007; Woods-Ballard et al, 2007). Increased interest, however, has raised in CWs, because of the multiple benefits they afford, including low energy and cost input, water quality enhancement, flood moderation, and environmental amenities (Vymazal, 2010). 
Within the best management practices context, CWs and constructed ponds are increasingly utilized for the treatment of a variety of contaminants, including agricultural, urban and highway runoff, wastewater, mine and other industrial water effluent types. They aim to moderate and control the impact of source and non-point source water pollution, affording environmentally friendly and promising infrastructure (Vymazal \& Březinová, 2015). Beyond purification properties, CWs and ponds offer a variety of services, including flood moderation, ecological and recreational use.

It is helpful to distinguish between ponds and wetlands, because they afford different hydraulic and hydrological features, eventually resulting in different water quality processes. Constructed ponds are typically small manufactured open-water bodies with little water stage fluctuation, and usually limited marginal vegetation; whereas CWs are shallow detention systems, with occasionally intermittent water flow, and are normally covered with emergent aquatic plants (Persson et al, 1999).

The competence of CWs in removing a diversity of pollutants is registered and ratified by numerous internationally published studies to-date (most recently including: Diaz et al, 2012; Fia et al, 2013; Lee et al, 2015; Pappalardo et al, 2016; Rossmann et al, 2013; Selvamurugan et al, 2010; Tournebize et al, 2015). Nevertheless, the main focus of research in CWs and ponds has been directed on treatment processes, i.e. biological and chemical, comparing in-/outgoing concentrations of pollutants. However, this approach treats the systems as black boxes, overlooking that the physical flow characteristics is a key transport and removal means of the pollutant, and hence, a key factor of the overall system performance (Polprasert \& Bhattarai, 1985; Kadlec, 1994; Min \& Wise, 2009). As a consequence, there has been less research dedicated to the hydraulic performance of systems, to the investigation of design parameters related to hydraulic processes, and to the interdependence between hydraulic and water quality processes.

Prediction of the downstream pollution levels poses a current challenge to designers and modellers of CWs. Understanding and knowledge around mixing processes in vegetated flows is still an area of research, especially in full-scale units. The presence of vegetation influences mixing properties in the 
units, whilst non-idealised geometrical shapes and channel irregularities contribute to non-uniform flow fields. In addition, treatment efficacy is related to hydraulic residence time, and thus discharge of effluents at shorter residence times than the designed is undesirable. Treatment efficacy is, furthermore, linked to mixing processes, since pollutant concentrations downstream are expected to abate through spread and dilution, and through degradation processes. Understanding how pollution transports in vegetated flows and in large-scale non-idealised shaped units will provide information that has been restricted by studies using artificial vegetation or conducted in idealised small-scale laboratory conditions.

Factors that importantly determine the performance of aqueous systems involve hydrological and meteorological elements (Persson \& Wittgren, 2003), and actual system shape (Persson, 2000). It is generally agreed that the hydraulic residence time (HRT) dictates the removal efficacy, and is principally connected to hydrological conditions (Dierberg et al, 2002). Furthermore, Lee et al (2015) highlighted that rainfall intensity, rainfall depth, and antecedent dry days are critical components in the removal of diffused pollutants. The overall hydrodynamics of CWs are highly dependent upon the aspect ratio $\left(A_{R}\right)$, the in-/outlet arrangement, and obstructions designation and layout, i.e. vegetation, isles etc. (Persson et al, 1999). Importantly, Johannesson et al (2015) noted high dependence between pollutants' retention and CW $A_{R}$, recommending higher aspect ratios for better treatment. Therefore, it is apparent that the hydraulic design of the treatment unit should not be ignored.

The hydraulic efficiency, $\lambda$, lies within the wider context of hydraulic performance, and is a measure expressing the combined effects of the distribution of incoming water in the system and of the amount of mixing in the system (Persson et al, 1999). Several studies have investigated factors that influence hydraulic performance of CWs and ponds, and have tried to optimise the systems and to provide general design guidelines (Aguwamba, 2006; Bodin et al, 2012; Diaz et al, 2012; German et al, 2005; Holland et al, 2004; Jadhav \& Buchberger 1995; Koskiaho, 2003; Persson et al, 1999; Persson, 2000; Somes et al, 1999; Su et al, 2009; Wörman \& Kronnäs, 2005). Nevertheless, the 
majority of those studies was either conducted via simulations (which overlooks the field effects), or has neglected vegetation (which affects the hydrodynamics). In order to add further knowledge and rigour on the $\mathrm{CW}$ and pond hydrodynamics, studies have been undertaken using empirical data (lab or field), and vegetation (synthetic, dowel, or real) (Chyan et al, 2014; Nepf et al, 1997; Nepf, 1999; Nepf, 2012; Shucksmith, 2008; West, 2016).

This paper presents empirical data obtained in full-scale cells of free-water surface CWs and lagoons in the UK. The primary aim of this paper is to investigate, quantify and assess the impact of design features on the hydraulic behaviour and on the mixing and physical flow characteristics in assorted shaped and full-size treatment units on the actual site. The ultimate objectives intend to contribute to the current body of knowledge by: i) applying and assessing the current theoretical understandings developed in idealised conditions, thus including the field effects; ii) evaluating the effect of size of a treatment unit on the contaminant dispersion, and thus on treatment efficiency; iii) understanding the effect of various design parameters on hydraulic performance, improving the design guidelines; iv) underlining the importance of investigating hydrodynamics and physics of flow in treatment units, besides the sole focus on treatment performance.

\section{METHODOLOGY - EXPERIMENTAL SETUP}

\subsection{The Cases Studied}

Six full-size investigation sites were studied (four CWs and two lagoons). The topographic map and details of each unit are provided in this section. The geometric characteristics, influent type, and location of the systems are summarised in Table 2.1.

Table 2.1. Geometric characteristics of the investigated systems, influent type, and location.

Two CWs are located in the RSPB farm, Cambridgeshire, and are in-series, connected via a 115m open channel, with South Wetland 1 (SW1) upstream, and South Wetland 2 (SW2) downstream, as 
illustrated in Figure 1. Both units are shallow and unbunded, with fully emergent vegetation, Phragmites australis. Flow depends on precipitation.

Figure 1: Schematic plan view for the in-series SW1 and SW2.

North Wetland (NW) is located at the north part of the RSPB farm, Cambridgeshire. This unit is deeper compared to SWs, as it is bunded at the outlet, i.e. water is discharged via a closed pipe (see Figure 2). Flow regime is intermittent and depends on rainfall. Phragmites australis is the main plant species.

Figure 2: Schematic plan view for NW.

The A-Winning Minewater Treatment Scheme (A-WMTS) includes a CW in Derbyshire. The unit has two inlets, as seen in Figure 3, each of which receives water from an upstream lagoon; incoming water is distributed across a weir at the inlet. The unit has two outlets, and treated water ends up into the adjacent brook. Water is pumped at a constant rate, whilst vegetation is fully emergent common reeds (Phragmites australis). It has to be noted that in January 2016 lagoon A broke down, thus disrupting the two inlet normal inflow conditions. Investigation of the single inlet inflow configuration was conducted to assess the hydraulic performance and mixing characteristics.

\section{Figure 3: Schematic plan map for A-WMTS.}

Clough Foot minewater treatment scheme (located Yorkshire) consists of two identically sized lagoons, operating in parallel arrangement. There is a control, and a baffled system, with the latter having been retrofitted using curtains, in order to enhance lagoon hydraulics. The schematic of the baffled system is shown in Figure 4. Control lagoon is identical, excluding the baffle curtains.

Figure 4: (Left) Clough Foot Baffled Lagoon, indicating curtain locations, orientations and flow path through the lagoon. (Right) Baffle curtains (Taken from Chamberlain \& Moorhouse, 2016). 


\subsection{Hydraulic Tracer Tests}

In order to derive the residence time distribution (RTD) and describe the systems hydraulically, fluorescent dye Rhodamine WT was used as tracer, injecting an impulse at the inlet of each system. Fluorescent tracer concentrations were determined at the outlet using Cyclops-7 fluorometers.

\subsection{Background on wetland hydraulic theory}

In plug flow theory, it is customary to adopt the theoretical or nominal residence time, $t_{n}$. This is denoted as the fraction of wetland volume, $V_{t o t}$, over discharge, $Q$. However, this basic standard rule might not fit well in actual wetland conditions, due to variations in flow velocity, heterogeneous mixing processes (i.e. bed topography and spatial vegetation distribution), and wind interference, all of which create a distribution of residence times in each water particle entering the system, ultimately leading to a distribution of travel times. Such deviations from the ideal pattern cause some water particles to depart earlier or later from the system, resulting either in short-circuiting or dead zones respectively (Thackston et al, 1987). The RTD function $E(t)$ is defined in Equation 1:

$$
E(t)=\frac{Q(t) C(t)}{\int_{0}^{\infty} Q(t) C(t) d t}=\frac{Q(t) C(t)}{\sum_{i=1}^{n} Q(t) C(t) d t}
$$

where $E(t)=$ RTD function $\left(\mathrm{s}^{-1}\right) ; Q(t)=$ outlet flow rate at time $\mathrm{t}\left(\mathrm{m}^{3} \mathrm{~s}^{-1}\right) ; C(t)=$ outlet tracer concentration at time $\mathrm{t}(\mathrm{ppb}) ; t=$ sampling time $(\mathrm{s}) ; d t=$ sampling time interval $(\mathrm{s})$.

The mean residence time, $t_{m}$, also known as HRT, is the average time that a tracer particle stays in the system, defined as the first moment of the RTD, given in Equation 2:

$$
t_{m}=\int_{0}^{\infty} t E(t) d t=\sum_{i=1}^{n} t E(t) d t \quad \text { (Equation 2) }
$$

Variance, $\sigma^{2}\left(\mathrm{~s}^{2}\right)$, is a measure of the RTD spread and corresponds to the second moment, computed by Equation 3: 


$$
\sigma^{2}=\int_{0}^{\infty}\left(t_{m}-t\right)^{2} E(t) d t=\sum_{i=1}^{n}\left(t_{m}-t\right)^{2} E(t) d t \quad \text { (Equation 3) }
$$

Employing the concept of Taylor (1953), longitudinal dispersion can be characterised by Equation 4 . $D_{x}$ encompasses the effects of velocity shear and turbulent mixing.

$$
\mathrm{D}_{\mathrm{x}}=\frac{\mathrm{u}^{2}}{2} \frac{\mathrm{d} \sigma_{\mathrm{t}}^{2}(\mathrm{x})}{\mathrm{dt}}
$$

where $\mathrm{u}=$ longitudinal velocity $(\mathrm{m} / \mathrm{s})$.

The hydraulic efficiency, $\lambda$, is a measure of the system's ability to distribute the flow evenly within the occupying water volume, and also to achieve adequate mixing or recirculation. Persson et al (1999) have classified $\lambda$ into bands of good (i.e. $\lambda>0.75$ ), satisfactory (i.e. $0.5<\lambda \leq 0.75$ ), and poor (i.e. $\lambda \leq 0.50$ ). The $\lambda$ in this paper was calculated by Equation 5 (Bodin et al, 2012; Chyan et al, 2014), because it is considered as a more realistic value of the system's efficiency:

$$
\lambda=\frac{t_{p}}{t_{m}}=e \cdot\left(1-\frac{1}{N}\right)
$$

in which $t_{p}=$ peak concentration time (s) of RTD, and $\mathrm{N}=$ the number of the equally sized completely stirred tank reactor (CSTR) tanks used in the tank in series (TIS) mass transport model (Levenspiel, 1966). As such, a completely mixed reactor is represented by one TIS ( $\mathrm{N}=1$ ), while plug flow corresponds to infinite number of TIS $(\mathrm{N}=\infty)$.

The shortest travel time, $t_{1}^{\prime}$, from the inlet to the outlet identifies a common index for short-circuiting. This refers to the quickest flow path in the system and corresponds to the first arrival time of the tracer at the outlet. Another commonly used short-circuiting index is $t 10$, which is the $10^{\text {th }}$ percentile of the tracer having exited the outlet. Two further short-circuiting indices employed in this paper were $t_{50} / t_{n}$ and $t_{16} / t_{n}$. 


\section{RESULTS \& DISCUSSION}

In this study, four CWs and two lagoons were assessed for their hydrodynamic properties. RTD curves are initially analysed qualitatively to define the general hydrodynamic trends in each system. Secondly, transport parameters obtained from the RTD analyses are compared (see Table 3.1). Lastly, discussion and general conclusions and recommendations are drawn from the empirical data, to add rigour and knowledge in the current operational and design of $\mathrm{CW}$ and ponds.

\subsection{Qualitative Analysis of the RTD curves}

A summary of the hydrodynamic transport parameters derived from the RTD analysis for each selected test are listed in Table 3.1, where columns refer to each aqueous system, and rows present an assortment of parameters related to hydrodynamic, mixing and physical flow characteristics. RTDs were obtained by monitoring the tracer concentration at the outlet of each system, and are presented in Figure 5 (a)-(f), allowing assessment of the global flow trends. In particular, there is a strong correlation between the left side plots in Figure 5 ((a), (c), and (e)), indicating strong short-circuiting, whereas the right side plots in Figure 5 ((b), (d), (f)) undergo distinctly lower amount of shortcircuiting, larger amount of active volume, and greater dispersion mainly due to the prolonged tails.

The left side plots in Figure 5 ((a), (c), and (e)), present a type of RTD that combines plug flow with some longitudinal mixing, according to Danckwerts (1953). Furthermore, the fact that $t_{m}$ is very early compared to the expected $t_{n}$ demonstrates that preferential paths are prevalent in those systems, while minimal longitudinal mixing takes place, as suggested by the short trailing edges. These tails occur because the residual of the dye mixed in the main volume, takes slightly longer time to exit the system. It is remarked that the high short-circuiting noticed in the Control Lagoon, is attributed to the buoyancy effect from water temperature, as observed from the Rhodamine WT and the visible water vapours. The tracer rapidly traverses the Control Lagoon, utilising only the top layer of the water column, eventually leaving intact the majority of the total available volume. On the other hand, shortcircuited flows in SWs are attributed primarily to the downstream unbunded (non-dammed) layout. 
That condition does not support water hold-back in the system, and promotes stream-like rather than wetland function.

Table 3.1: Hydrodynamic transport parameters obtained from RTD analyses.

The right side plots in Figure 5 ((b), (d), (f)) indicate distinctly lower short-circuiting, larger effective volumes, $e$, and greater dispersion. The RTDs of the Baffled Lagoon and of the NW suggest plug flow with longitudinal mixing, while the A-WMTS RTD demonstrates large active volume and a large quantity of stagnant backwaters.

Figure 5: Compiled RTD curves for each case study.

\subsection{Quantitative Assessment of Transport Parameters}

In order to evaluate quantitatively the hydrodynamics of the six studied aqueous systems, transport parameters were derived from the individual RTDs (see Table 3.1). Comparison, discussion and interpretation of the characteristics of the systems takes place in the following sections, in terms of hydraulic performance parameters, and flow and mixing characteristics.

\subsubsection{Hydraulic residence time (HRT), effective volume (e)}

The six investigated systems were of different size (see Table 2.1), and thus, of different nominal residence times, $t_{n}$. However, of similar size were the three RSPB CWs, namely SW1, SW2, NW. Based on the system size (i.e. total available volume from all three dimensions), the measured HRTs (or $t_{m}$ ) should follow the order of: Clough Foot Lagoons $>$ A-WMTS $>$ NW $>$ SW1 $>$ SW2. This assumption is ratified by the $t_{m}$ values obtained (see Table 2.1). Nevertheless, HRTs of the Control Lagoon, SW1 and SW2 were too far from their relevant expected $t_{n}$ value, which imply highly shortcircuited flows, whereas the Baffled Lagoon and NW displayed smaller divergence between those values. Consequently, the effective volume, $V_{\text {eff, }}$ in the Control Lagoon, SW1 and SW2 was significantly lower compared to the design volume. This stresses the need for appropriate selection 
of design parameters (particularly to avoid dead zones and to reduce preferential flow paths). In contrast to the above, HRT in A-WMTS was close to the corresponding $t_{n}$ value, implying large active volumes, i.e. $e \approx 0.8$. According to Thackston et al (1987), based on the e-values, the Control Lagoon encounters big quantities of dead zones, while SW1, NW and Baffled Lagoon undergo moderate amounts of dead zones. It is of note that the baffled curtains retrofit increased significantly the proportion of the active volume in the lagoon (i.e. approximately 3 times), albeit the post retrofit evalue still indicates significant dead water volumes, inferring the need for further improvement of the internal hydraulics.

Related to the aggregated dead zone model (Beer \& Young, 1983), dispersive fraction, $D_{f}$, is a parameter that quantifies the ratio of the river reach acting as a dead zone to the total reach volume; therefore, it indicates the ratio of the reach responsible for the dispersion of the tracer. As such, variation in $D_{f}$ might be comparable to the $D_{x}$. $D_{f}$ values closer to unity indicate high proportion of dead zones. Results showed lower, but similar, $D_{f}$ values in SW1 and SW2, whilst maximum and same, $D_{f}$ values in the Clough Foot Lagoons (see Table 3.1). It is of interest, that the baffle curtains retrofit did not contribute to any reduction of the $D_{f}$ fraction, thus implying high proportion of dead regions, albeit the flow regime has turned into plug flow.

\subsubsection{Hydraulic Efficiency $(\lambda)$}

There is some differentiation between hydraulic performance and efficiency. Hydraulic performance is set in a wider context, covering more elements of flow conditions (e.g. shortcircuiting), and is overall less value-oriented (Persson, 2000). On the other hand, hydraulic efficiency, $\lambda$, indicates both how well the incoming water distributes in the system, and also the amount of mixing or recirculations (Wong \& Somes 1995). By definition, $\lambda$ incorporates e, and (1-1/N), where the latter term describes the RTD shape. Therefore, high $e$ values do not necessarily entail high $\lambda$ values, as proved by Persson et al (1999). 
In several of the hypothetical cases Persson et al (1999) investigated, although e-value was very high, the RTD shape (expressed either as mixing, or as recirculation or stagnant backwaters) had a significant effect in reducing the final value of $\lambda$. For example, Somes et al (1998) investigated various options of channel bathymetries, and of vegetation layouts through simulations, and found that plug flow is not invariably the best case, as compromises may be needed for the $\mathrm{N}$ (i.e. selecting lower $\mathrm{N}$ in order to achieve increased mixing) in order to achieve enhanced $\lambda$ values. In this study, $\lambda$ is expressed as the ratio of $t_{p}$ over $t_{m}$, and the reason for choosing to use $t_{m}$ is to obtain the actual hydraulic efficiency of the system. Referring to Table 3.1, the use of $t_{n}$ for the estimation of $\lambda$ would not be representative of the actual conditions of the unit, due the overall large divergence between $t_{m}$ and $t_{n}$ in the majority of the treatment units.

\subsubsection{Flow patterns and Longitudinal Mixing}

Figure 5 (a)-(f) demonstrates that the Control Lagoon, SW1 and SW2 behave like plug flow reactors, with minimal longitudinal dispersion. The lower N in SW1 compared to SW2 is supported by the larger $D_{x}$ coefficient obtained in SW1. The flow pattern in NW and Baffled Lagoon shows some similarity, and suggests plug flow with some longitudinal dispersion. However, mixing is greater in the Baffled Lagoon, as demonstrated by the lower $\mathrm{N}$ value, and the greater $M o$ and $\mathrm{D}_{\mathrm{x}} / \mathrm{Wu}^{*}$ values. This indicates greater efficiency of baffles in promoting mixing. RTD obtained from AWMTS connotes a system with lots of dead water. In that context, the majority of the tracer passes through a restricted channel, while a considerable fraction of the tracer is caught in eddies and stagnant backwaters.

Overall, Peclet number, $P e$, reveals the degree of advective flow taking place in the order of: SW2 $>\mathrm{SW} 1>\mathrm{NW}$, which is consistent with the higher velocities observed (see Table 3.1). The mixing properties indicators, $\mathrm{N}$ and $M o=t 90 / t 10$, are consistent, following an ascending order as: $\mathrm{SW} 2>\mathrm{SW} 1$ $>$ NW > Baffled Lagoon > A-WMTS > Control Lagoon. This order connotes more plug flow conditions in SW2 and more mixing in Control Lagoon. In addition to this, the temperature buoyancy 
effect of the tracer in the Control Lagoon promoted the tracer to advect at the top surface layer straight through the lagoon, and contributed to the high Mo value obtained.

The dimensionless longitudinal mixing $D_{x} / \mathrm{hu}^{*}$, as employed in streams by Rutherford (1994), appears to receive comparable longitudinal mixing values between SW2 and Baffled Lagoon, and between SW1 and Control Lagoon. However, as those systems are totally different in terms of geometry (i.e. dimension, shape), flow depth, $h$, might not be the appropriate dimension to normalise $D_{x}$ in wetlands/ponds. As such, $D_{x}$ was also normalised by the width, $W$, of the treatment unit, as seen in Table 3.1. The relationship between the inverse of $P e$ (which is the Dispersion number) against normalised longitudinal dispersion coefficient using the $\mathrm{W}, D_{x} / \mathrm{Wu}^{*}$, is presented in Figure 6 (Left), where low 1/Pe values entail more advection. Figure 6 (Left) indicates a positive correlation between mixing (thus Dispersion number) and $\mathrm{W}$, and suggests that width plays an important role in the mixing and that the scale effects between the small and larger systems are minimal. However, given that $P e$ depends on length, $L, u_{\text {mean }}$ and $D_{x}$, there might be an expected relationship with the $D_{x} / \mathrm{Wu}^{*}$. Figure 6 (Right) presents 1/Pe against longitudinal dispersion coefficient normalised by flow depth, $h$ (thus $\left.D_{x} / \mathrm{hu}^{*}\right)$, and indicates that use of the $h$ between systems of different shape and scale does not provide a representative dimension to normalise the $D_{x}$. The difference is apparent particularly in the larger full-size units run by The Coal Authority (see Figure 6 (Right)).

Figure 6: $1 / \mathrm{Pe}$ against $\mathrm{D}_{\mathrm{x}} / \mathrm{Wu}^{*}$ indicating zero scale effects between the systems. (Right) 1/Pe against $\mathrm{D}_{\mathrm{x}} / \mathrm{hu}^{*}$ indicating different scale effects between the systems. Width appears to be a more important dimension compared to depth in affecting mixing characteristics in different scale systems.

Another element that influences the mixing degree is the aspect ratio, $A_{R}=L / W$. Persson (2000) underlines that the $\mathrm{CW} A_{R}$ does not only affect the effective volume ratio, $e$, but also the amount of dispersion. In particular, high $A_{R}$ promotes plug flow, and diminishes dispersion levels. Comparison of the $A_{R}$ with the $D_{x}$ values for each system, is not possible because of the different processes causing the dispersion in each system, and the different inflow and outflow conditions. However, a typical comparison between the Control and Baffled lagoons evidences that increase in $A_{R}$ (as happened after 
the retrofit) increased e and HRT, whilst it decreased $D_{x}$, promoting plug flow (Ioannidou \& Pearson, 2017).

The short-circuiting indices used in this study included $t_{1}^{\prime}, t_{10}, t_{16} / t_{n}$ and $t_{50} / t_{n}$. Greatest shortcircuiting was observed in SW1-2 and in the Control lagoon. This was instantly observed in left side Figure 5 , where the $t_{n}$ is substantially far from $t_{m}$, demonstrating that advection is the dominant flow pattern. However, despite NW being of similar shape and dimensions as SW1-2, it manages to retain the tracer 6 times longer, dissipate maximum and mean velocities at least by 5 times, while $t_{1}^{\prime}$ is 4 fold delayed. This is particularly attributed to the deeper outlet layout conditions, providing a good reference for $\mathrm{CW} /$ pond design construction.

Investigating the short-circuiting in the two identical lagoons, results suggest that the baffle curtains retrofitting attenuates short-circuiting at least by $50 \%$. Therefore, suggesting that simple system modifications, such as using obstacles or baffles of long width, can reduce radically shortcircuiting in a treatment unit.

\subsection{Comparative evaluation of the six investigated units}

A comparative evaluation of the hydraulic and treatment performance among the six treatment units is made in relation to various hydraulic performance parameters. In addition to this, recommendations to ameliorate the current hydraulics in each system, and general good design practices are discussed.

\subsubsection{Effect of Obstacles and Baffles on the HRT \& Hydraulic Performance}

HRT is an indication of the hydraulic and treatment performance, in such a way that longer HRT entails enhanced treatment (Dierberg et al, 2002; Lee et al, 2015; Stern et al, 2001; Pappalardo et al, 2016; Tournebize et al, 2016). HRT depends on the hydrology (i.e. water depth, flow rate), and hydraulics (i.e. obstructions, vegetation, and system shape, i.e. $A_{R}$ ) (Johannesson et al, 2015; Kadlec, 
1990; Jadhav \& Buchberger, 1995). Given the highest HRT in the Baffled Lagoon in comparison with the other five units, this system would probably exhibit the best efficiency for a variety of treatment effluents, i.e. municipal and industrial wastewater, agricultural and urban runoff.

HRT was very short in both SW1 and SW2; thus, it is inferred that their size, internal hydraulics and outlet configuration pose both SWs inadequate to achieve good treatment levels for agricultural runoff pollutants, as isolated individual units. However, the combined effects of a number of units in series, may be considered as summative, thus inducing further mitigation and reduction efficiency of agricultural runoff.

In the case of Clough Foot lagoons, it is observed that for the same system shape (i.e. control and baffled), the baffle curtains retrofit managed to increase significantly various hydraulic parameters, and in particular: $\lambda$ by 5 times (by 67\%), $e$ by 3 times (by 80\%), and HRT by 3 times (by 68\%), overall enhancing also the treatment efficacy (Ioannidou \& Pearson, 2017). In particular, iron and aluminium removal increased by $41 \%$ and $34 \%$ respectively, after the retrofitting (Chamberlain \& Moorhouse, 2016). This underlines the interdependence between hydraulic and treatment performance, stresses the need to study both fields of sciences closely, and underpins that internal hydraulics and physics of flow should not be overlooked. The difference between the hydraulic and treatment efficiency, possibly results from existing large dead regions in the Baffled Lagoon, which most likely occurs either due to the thermal stratification or due to the need of further retrofitting practices to reduce the stagnant backwaters. Another reason could be the different season that the tracer (i.e. February) and the metal monitoring data (May-October) was undertaken, entailing less thermal stratification effect over summer months.

\subsubsection{Short-Circuiting \& Hydraulic Optimisation}

In terms of optimising hydraulically the available volume, SW2 appears to combine very good $\lambda$ and $e$ values, implying that the impact of stagnant backwaters on the pollutant mitigation mechanisms 
is minimal. However, SW2 functions as a well-mixed pipe or stream, as demonstrated by the RTD profile (Figure 5 (e)) and from the high short-circuiting levels, thus is deemed as poor construction in terms of treating pollutants as is. Therefore, taking into consideration the HRT, $\lambda$ and $e$ values, both NW and A-WMTS systems would be considered the best ones to mitigate treatment effluents more efficiently, compared to the other treatment units.

Considering internal configuration improvement, baffle curtains retrofit managed to reduce notably the short-circuiting levels. Su et al (2009) recommended implementation of obstructions to enhance the hydraulic efficiency of a treatment unit, if that is poor by construction. Furthermore, the authors found that the number of obstructions is not so important, as is their width, to enhance $\lambda$ and to reduce internal recirculations. It is recommended that $A_{R}$ must be at least larger than 1.88 to allow for $\lambda>0.7$ (Su et al, 2009). However, despite fulfilling the $A_{R}$ criterion in all the six examined units of this study, it was not necessarily achieved $\lambda$ or $e$ values close to, or larger than 0.7 . Furthermore, Su et al (2009) recommended $A_{R}>5$ to achieve $\lambda>0.9$, case that is observed to apply merely for the SW2. The divergence of Su et al's (2009) design recommendations indicate that they should be dealt only as indicators, probably mainly because their results were produced through numerical simulations, and refer to ideal shapes (thus omitting the field effects), which is rarely the case in reality. Nevertheless, a combination of a bunded outlet in conjunction with rectangular obstacles, within internal configuration, in SW1 and SW2 is expected to improve significantly their current performance.

\subsubsection{Effect of Inflow Condition on Hydraulic Performance}

The inflow configuration has an effect on short-circuiting and effective volume of the treatment unit. Persson (2000) demonstrated that having an inlet along the whole base reduces short-circuiting, enhances significantly the active volume and hydraulic efficiency, and decreases the amount of mixing. Su et al (2009) investigated various ways to improve the hydraulic performance in CWs, demonstrating that uniform inflow spreading is the best possible inflow configuration that can be 
implemented at the inlet. In the units operated by The Coal Authority, i.e. A-MWTS, Control and Baffled Lagoons, the inlet configuration approximates the recommended uniform inflow spread.

In A-WMTS in particular, during normal inflow operational conditions (i.e. operation of both lagoons), inflow occurs via two inlets and spreads across a large weir (see Figure 3). The active volume achieved is $80 \%$, although the RTD profile indicated stagnant backwaters (Figure 5 (f)). In addition to this, tracer tests showed that Rhodamine WT was not instantly spread uniformly across the inlet, but followed initially a specific preferential path (Figure 7), and afterwards it became well mixed.

Figure 7: Tracer route during the normal inflow operational condition. Tracer takes an initial preferential path (Photo taken 3/12/15).

As soon as pumping to lagoon A failed, normal inflow conditions were disrupted. The single-inlet configuration (i.e. single lagoon operation) promoted a different flow regime, where inflow was forced toward the low flow velocity zone, at the right side of the inlet weir (Figure 8 (a)), and influent spread more slowly, following a different route, which used the right side of the wetland (Figure 8 (b)). At the single-inlet condition, tracer/pollutant followed a different path as entering the CW, experiencing lower initial velocity as entering the system, because the tracer is stuck at the corner of the inlet weir and reverses slowly back into the main flow. It is noteworthy that flow rate was maintained the same during the single-inlet inflow period, with all inflow passing through one inlet (from lagoon B, see Figure 3). The single-inlet condition was found to support internal recirculation and inadequate mixing of the solute in the wetland, as demonstrated by the raw concentration data obtained through two tracer tests, presented in Figure 9 (a) - (b). This actual case study evidences the central role of inlet configuration in the flow regime, mixing characteristics, and thus pollutant treatment efficacy of large full-scale units.

Figure 8: Tracer route during the single-lagoon inflow condition. Tracer is forced at the low flow velocity zone and spreads more slowly, following a different route (Photos taken 21/01/16). 
Figure 9: RTDs for post lagoon A breakdown period effects in A-WMTS. Fig. (a)-(b) indicate the recirculated currents promoted after the one inlet operation in April (a) and in May (b).

\subsubsection{Effect of Outlet Layout on Hydraulic \& Mixing Properties}

The three RSPB CWs are by construction of similar size and shape, however, they differ mainly because of their outlet configuration. The main differentiation between NW and SWs is that NW is controlled downstream by an elevated pipe, established in an embankment, while SWs are unbunded at the outlet. The difference between unbunded and bunded outlet layout results in two contrasting flow conditions, namely shallow operational depths for the SWs, which lead to a flow-through regime, and deeper operational depths for the NW, which result into dissipated velocities in NW (and frequently to detention or ponding).

SWs operate normally between 0.1 and $0.2 \mathrm{~m}$ average flow depths, while NW allows for $0.3 \mathrm{~m}$ as a mean detention or ponding flow depth, before it flushes through the pipe, whereas when discharging through the pipe, water depth may reach 0.4 to $0.5 \mathrm{~m}$, depending on the flow rate. Instantly, it is clear that NW allows for two operations: i) detention or ponding of effluent, occurring when flow depth is below the exit pipe; and ii) approximately twice deeper operational depths compared to SWs, and dissipated velocities. As a consequence, HRT in NW is in the order of hours, whilst in SWs in the order of minutes. Furthermore, $\mathrm{N}$ is significantly decreased in $\mathrm{NW}$, indicating more complete mixing conditions, while the lower $P e$ implies less advection, and more longitudinal dispersion, as suggested also by the Mo index. In addition to this, better spread and mixing in NW is advocated by the dimensionless variance, $\sigma_{\theta}^{2}$ (see Table 3.1). The downstream outlet construction promoted dissipated flow velocities, as shown by the nearly laminar flow regime in NW, and resulted in exertion of lower pressure on stems, preventing stems deflection.

Biochemical data collected in the three RSPB CWs for the potential of mitigating particular pesticides, were presented in the ERAR CRD Annual Meeting in 2016 (Whelan, 2016), and showed 
that SWs, as continuous flow-through systems, presented no significant difference in certain pesticides (i.e. metaldehyde and carbetamine), while the mitigation capacity of the intermittent flow regime existing in NW was underlined. In particular, NW managed to abate significantly certain pesticides (i.e. quinmerac, metazachlor, metaldehyde), particularly because of the detention capacity of this unit, which allows for treatment time between two storm-flushing through the pipe events. This sheds some light to previous research conducted by Diaz et al (2012), who hypothesised that continuous flow-through CWs seem more effective in removing a variety of agricultural non-point source (NPS) pollutants, compared to flood-pulse hydrologic regime, which resembles the NW intermittent flow regime (Ioannidou, 2017).

\section{CONCLUSIONS}

The present study investigated six full-scale treatment units of different hydrodynamic properties and design parameters. A comparative evaluation among the units showed that internal hydraulics are significantly affected by design parameters and by smooth operational conditions, such as even inflow distribution of influent. In particular, baffles improved the hydraulic performance by a factor of three and reduced the treated effluent concentration by five times. Disturbance of the even inflow conditions was found to result in poor mixing of the treated effluent and in continuous internal sluggish recirculations. Furthermore, it was demonstrated that construction of a bunded outlet configuration can improve significantly the mixing characteristics (i.e. greater contaminant spread and reduction of the peak concentration by up to 10 times), and the hydraulic performance.

Overall, results pinpointed that hydraulic performance is intrinsically connected with the treatment performance, and should not be overlooked, but should be looked in parallel instead. Of significant note is the finding that the width of the treatment unit is a more important dimension for the longitudinal mixing compared to the depth. Finally, hydraulic optimisation guides do not necessarily conform with hydraulic parameters and values obtained from large full-scale units, indicating the 
need to investigate more full-sized applications on the actual site in order to cover the gap between simulations and reality (e.g. field effects). 


\section{REFERENCES}

Agunwamba, J.C. (2006). Effect of the location of the inlet and outlet structures on short-circuiting: Experimental investigation. Water environment research, 78(6), 580-589.

Beer, T. \& Young, P.C. (1983). Longitudinal dispersion in natural streams. Journal of environmental engineering, 109(5), 10491067.

Bodin, H., Mietto, A., Ehde, P.M., Persson, J. \& Weisner, S.E.B. (2012). Tracer behaviour and analysis of hydraulics in experimental free water surface wetlands. Ecological Engineering, 49, 201-211.

Chyan, J. M., Tan, F. J., Chen, I. M., Lin, C. J., Senoro, D. B., \& Luna, M. P. C. (2014). Effects of porosity on flow of free water surface constructed wetland in a physical model. Desalination and Water Treatment, 52(4-6), 1077-1085.

Danckwerts, P.V. (1953). Continuous flow systems: Distribution of residence times. Chemical Engineering Science, 2(1), 1-13.

Diaz, F.J., O’Geen, A.T., Dahlgren, R.A. (2012). Agricultural pollutant removal by constructed wetlands: Implications for water management and design. Agricultural Water Management, 104, 171-183.

Dierberg, F. E., DeBusk, T. A., Jackson, S. D., Chimney, M. J., \& Pietro, K. (2002). Submerged aquatic vegetation-based treatment wetlands for removing phosphorus from agricultural runoff: response to hydraulic and nutrient loading. Water research, 36(6), 14091422 .

European Commission, 2006. Bathing water quality - Legal Obligations under the EU Bathing Water Directive 2006/7/EC. Available at: http://ec.europa.eu/environment/water/water-bathing/summary.html

European Commission, 2000. The EU Water Framework Directive - integrated river basin management for Europe. Available at: http://ec.europa.eu/environment/water/water-framework/index_en.html

Fia, R., de Matos, A. T., \& Fia, F. R. L. (2013). Biological systems combined for the treatment of coffee processing wastewater: IIRemoval of nutrients and phenolic compounds. Acta Scientiarum. Technology, 35(3), 451-456.

German, J., Jansons, K., Svensson, G., Karlsson, D. \& Gustafsson, L. G. (2005). Modelling of different measures for improving removal in a stormwater pond. Water Science \& Technology, 52(5), 105-112.

Holland, J.F., Martin, J.F., Granata, T., Bouchard, V., Quigley, M. \& Brown, L. (2004). Effects of wetland depth and flow on residence time distribution characteristics. Ecological Engineering, 23, 189-203.

Ioannidou, V.G. (2017). Solute Mixing in Full-Scale Constructed Wetlands: Seasonal Variations of Vegetation \& Hydraulic Performance. PhD Thesis. University of Warwick, UK.

Ioanndou, V.G. \& Pearson, J.M. (2017). Case studies investigating hydraulic parameters in full-scale constructed wetlands. European Water Journal, 58, 151-158. EWRA2017 - 10th Word Congress on Water Resources and Environment

Jadhav, R.S., Buchberger, S.G., 1995. Effects of vegetation on flow through free water surface wetlands. Ecol. Eng. 5, 481-496.

Johannesson, K. M., Kynkäänniemi, P., Ulén, B., Weisner, S. E. B., \& Tonderski, K. S. (2015). Phosphorus and particle retention in constructed wetlands-A catchment comparison. Ecological Engineering, 80, 20-31.

Kadlec, R. H. (1990). Overland flow in wetlands: vegetation resistance. Journal of Hydraulic Engineering, 116(5), 691-706.

Kadlec, R.H. (1994). Detention and mixing in free water wetlands. Ecological Engineering, 3, 345-380.

Koskiaho, J. (2003). Flow velocity retardation and sediment retention in two constructed wetland-ponds. Ecological Engineering, 19, 325-337.

Lee, S. H., Cha, S. M., Lee, J. C., \& Lee, J. Y. (2015). Performance Evaluation of the Free Water Surface Constructed Wetland Treating Nonpoint Source Pollutants in the Agricultural Area. Journal of Environmental \& Analytical Toxicology, 5(4), 1.

Min, J. H. \& Wise, R. W., (2009). Simulating short-circuiting flow in a constructed wetland: the implications of bathymetry and vegetation effects. Hydrological Processes, 23, 830-841.

Nepf, H.M., Mugnier, C.G. \& Zavistoski, R.A. (1997). The effects of vegetation on longitudinal dispersion. Estuarine, Coastal and Shelf Science, 44, 675-684.

Nepf, H.M. (1999). Drag, turbulence, and diffusion in flow through emergent vegetation. Water Resources Research, 35(2), 479489. 
Nepf, H. M. (2012 a). Hydrodynamics of vegetated channels. Journal of Hydraulic Research, 50(3), 262-279.

Pappalardo, S. E., Otto, S., Gasparini, V., Zanin, G., \& Borin, M. (2016). Mitigation of herbicide runoff as an ecosystem service from a constructed surface flow wetland. Hydrobiologia, 774(1), 193-202.

Persson, J., Somes, N.L.G. \& Wong, T.H.F. (1999). Hydraulics efficiency of constructed wetlands and ponds. Water Science and Technology, 40(3), 291-300.

Persson, J. (2000). The Hydraulic Performance of Ponds of Various Layouts. Urban Water, 2, 243-250.

Persson, J., \& Wittgren, H. B. (2003). How hydrological and hydraulic conditions affect performance of ponds. Ecological Engineering, 21(4), 259-269.

Polprasert, C. \& Bhattarai, K.K. (1985). Dispersion model for waste stabilization ponds. Environmental Engineering, 111(1), 4559.

Rossmann, M., Matos, A. T., Abreu, E. C, Silva, F. F. \& Borges, A. C. (2013). Effect of influent aeration on removal of organic matter from coffee processing wastewater in constructed wetlands. Journal of Environmental Management, 128, 912-919.

Rutherford, J.C. (1994). River mixing. Chapter 4, Longitudinal Dispersion. John Wiley \& Sons, Inc., Chichester, U.K.

Scholz, M., Harrington, R., Carroll, P., \& Mustafa, A. (2007). The integrated constructed wetlands (ICW) concept. Wetlands, 27(2), 337-354.

Selvamurugan, M., Doraisamy, P., \& Maheswari, M. (2010). An integrated treatment system for coffee processing wastewater using anaerobic and aerobic process. Ecological Engineering, 36(12), 1686-1690.

Shucksmith, J. D. (2008). Impact of vegetation in open channels on flow resistance and solute mixing (Doctoral dissertation, Sheffield).

Somes, N. L. G., Persson, J., \& Wong, T. H. F. (1998). Influence of wetland design parameters on the hydrodynamics of stormwater wetlands. Hydrastorm, Adelaide, 27(30), 123-128.

Stern, D.A., Khanbilvardi, R., Alair, J.C. \& Richardson, W. (2001). Description of flow through a natural wetland using dye tracer tests. Ecological Engineering, 18, 173-184.

Su, T.M., Yang, S.C., Shih, S.S. \& Lee, H.Y. (2009). Optimal design for hydraulic efficiency on free-water-surface constructed wetlands. Ecological Engineering, 35, 1200-1207.

Taylor, G.I. (1953). Dispersion of soluble matter in solvent flowing slowly through a tube. Proceedings of the Royal Society A, 219, 186-203.

Thackston, E.L., Shields, D. \& Schroeder, P.R. (1987). Residence time distributions of shallow basins. Journal of Environmental Engineering, 113(6), 1319-1332.

Tournebize, J., Chaumont, C., Fesneau, C., Guenne, A., Vincent, B., Garnier, J., \& Mander, Ü. (2015). Long-term nitrate removal in a buffering pond-reservoir system receiving water from an agricultural drained catchment. Ecological Engineering, 80, 32-45.

Tournebize, J., Chaumont, C., \& Mander, Ü. (2016). Implications for constructed wetlands to mitigate nitrate and pesticide pollution in agricultural drained watersheds. Ecological Engineering. In press.

Vymazal, J. (2010). Constructed wetlands for wastewater treatment: five decades of experience. Environmental Science \& Technology, 45(1), 61-69.

Vymazal, J., \& Březinová, T. (2015). The use of constructed wetlands for removal of pesticides from agricultural runoff and drainage: a review. Environment international, 75, 11-20.

West, P. O. (2016). Quantifying solute mixing across low velocity emergent real vegetation shear layers (Doctoral dissertation, University of Warwick).

Whelan, M.J. 10 $0^{\text {th }}$ Annual Technical Meeting on Environmental Risk Assessment Research ERAR CRD. June 2016. University of York.

Woods-Ballard, B, Kellagher, R., Martin, P., Jefferies, C., Bray, R., \& Shaffer, P. (2007). The SUDS manual (C697). Available from: http://www.ciria.org/Resources/Free_publications/the_suds_manual.aspx

Wörman, A. \& Kronnäs, V. 2005. Effect of pond shape and vegetation heterogeneity on flow and treatment performance of constructed wetlands. Journal of Hydrology, 301, 123-128. 
Wu, M., Tang, X., Li, Q., Yang, W., Jin, F., Tang, M., Scholz, M. (2013). "Review of Ecological Engineering Solutions for Rural Non-Point Source Water Pollution Control in Hubei Province, China." Water, Air, \& Soil Pollution, 224(5), 1-18. 


\section{Figures / Tables}

Table 2.1. Geometric characteristics of the investigated systems, influent type, and location.

\begin{tabular}{|c|c|c|c|c|c|c|}
\hline & SW1 & SW2 & NW & A-WMTS & $\begin{array}{l}\text { Control } \\
\text { Lagoon } \\
\text { (Clough Foot) }\end{array}$ & $\begin{array}{c}\text { Baffled Lagoon } \\
\text { (Clough Foot })\end{array}$ \\
\hline General shape & Trapezium & Trapezium & Trapezium & Rectangular & Rectangular & Rectangular \\
\hline Length (m) & 34 & 32 & 32 & 105 & 64.5 & 64.5 \\
\hline Width (m) & (4.4) & (5.3) & (5.7) & 40 & 23.5 & 23.5 \\
\hline$A_{R}$ & 7.8 & 6.0 & 5.7 & 2.6 & 2.7 & 2.7 \\
\hline $\begin{array}{l}\text { Mean water depth } \\
\text { (m) }\end{array}$ & 0.15 & 0.16 & 0.46 & 0.5 & 3.8 & 3.8 \\
\hline Surface area $\left(\mathrm{m}^{2}\right)$ & 148 & 170 & 181 & 4,200 & 1,516 & 1,516 \\
\hline $\mathrm{V}_{\text {tot }}\left(\mathrm{m}^{3}\right)$ & 23.5 & 23.0 & 45.0 & 2,100 & 5,760 & 5,760 \\
\hline Vegetation & Phragmites & Phragmites & Phragmites & Phragmites & - & - \\
\hline Other obstacles & - & - & - & - & - & Baffle Curtains \\
\hline Influent type & $\begin{array}{l}\text { Agricultural } \\
\text { Runoff }\end{array}$ & $\begin{array}{l}\text { Agricultural } \\
\text { Runoff }\end{array}$ & $\begin{array}{l}\text { Agricultural } \\
\text { Runoff }\end{array}$ & Mine Water & Mine Water & Mine Water \\
\hline Location & Cambridge & Cambridge & Cambridge & Derbyshire & Yorkshire & Yorkshire \\
\hline
\end{tabular}




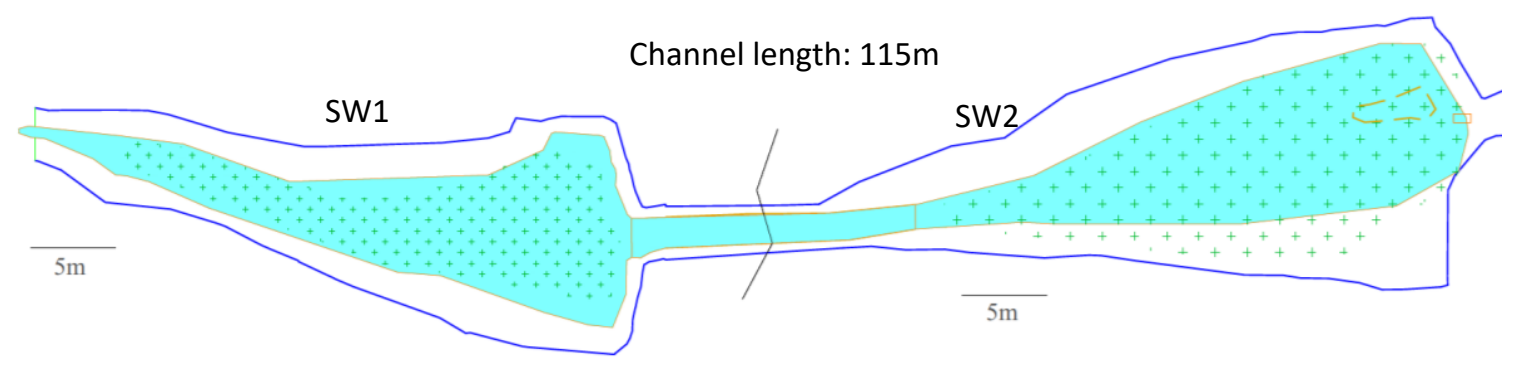

Figure 1: Schematic plan view for the in-series SW1 and SW2. 


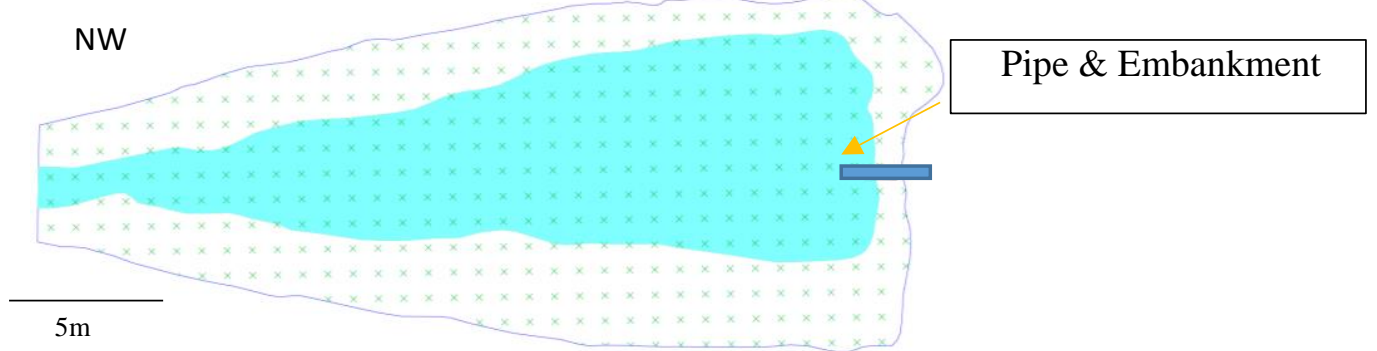

Figure 2: Schematic plan view for NW. 


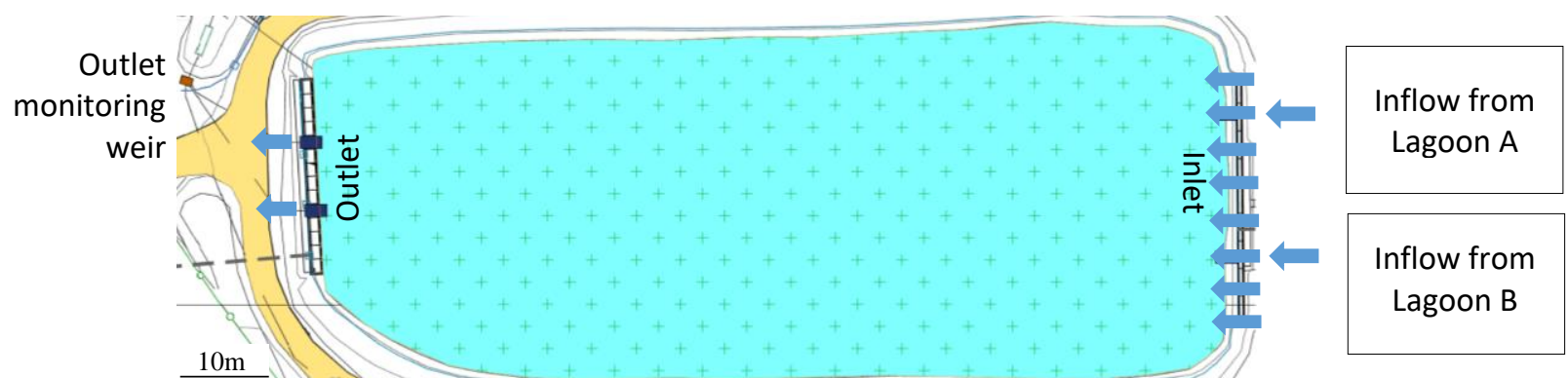

Figure 3: Schematic plan map for A-WMTS. 


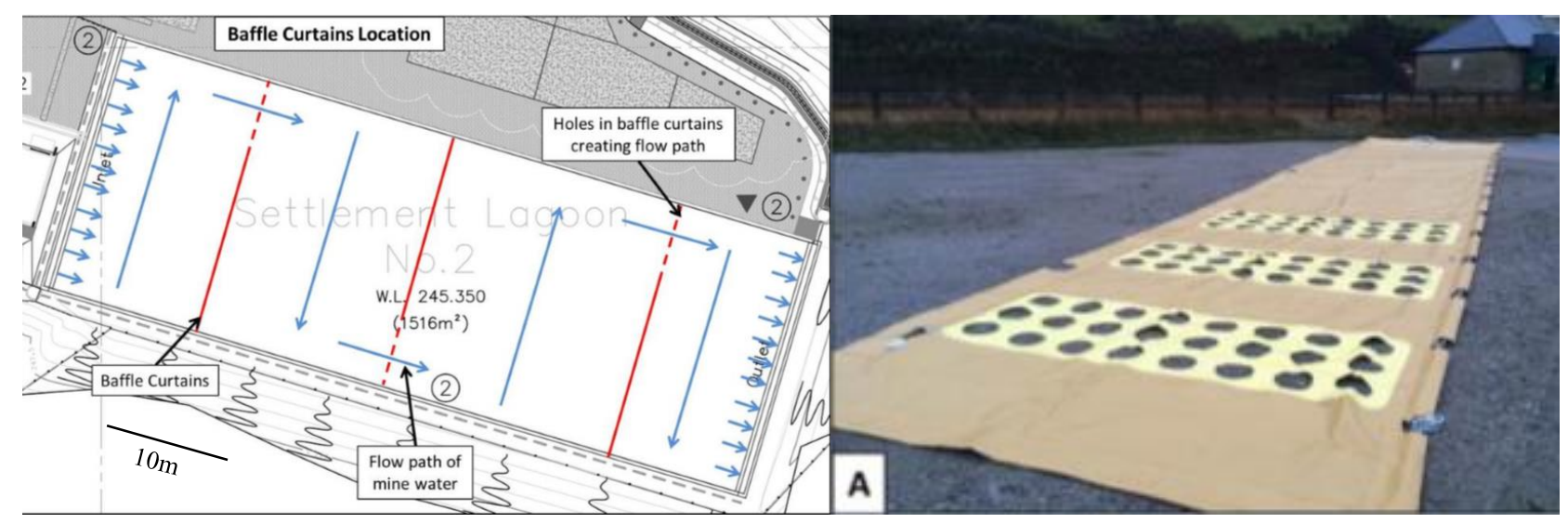

Figure 4: (Left) Clough Foot Baffled Lagoon, indicating curtain locations, orientations and flow path through the lagoon. (Right) Baffle curtains (Taken from Chamberlain \& Moorhouse, 2016). 
Table 3.1: Hydrodynamic transport parameters obtained from RTD analyses.

\begin{tabular}{|c|c|c|c|c|c|c|}
\hline & SW1 & SW2 & NW & A-WMTS & $\begin{array}{c}\text { Control } \\
\text { Lagoon } \\
\text { (Clough Foot) }\end{array}$ & $\begin{array}{c}\text { Baffled } \\
\text { Lagoon } \\
\text { (Clough Foot) }\end{array}$ \\
\hline $\mathrm{Q}(1 / \mathrm{s})$ & 20.4 & 22.9 & 5.0 & 70 & 15 & 15 \\
\hline Vegetation configuration & F. EM. (Dec) & F. EM. (Dec) & F. EM. (Dec) & F. EM. (Dec) & No Veg & No Veg \\
\hline$t_{1}^{\prime}$ & $7.5 \mathrm{~min}$ & $8.0 \mathrm{~min}$ & $0.72 \mathrm{~h}$ & $2.07 \mathrm{~h}$ & $1.6 \mathrm{~h}$ & $5.2 \mathrm{~h}$ \\
\hline $\mathrm{t}_{10}$ & $9.0 \mathrm{~min}$ & $9.9 \min$ & $0.97 \mathrm{~h}$ & $3.3 \mathrm{~h}$ & $3.0 \mathrm{~h}$ & $21.1 \mathrm{~h}$ \\
\hline$t_{16} / t_{n}$ & 0.46 & 0.61 & 0.42 & 0.43 & 0.04 & 0.25 \\
\hline$t_{50} / t_{n}$ & 0.54 & 0.69 & 0.55 & 0.64 & 0.12 & 0.45 \\
\hline$t_{p}$ & $10(\min )$ & $11.5(\min )$ & $1.2(h)$ & $3.7(h)$ & 2.1 & 34.6 \\
\hline$t_{n}$ & 20 (min) & 16.8 (min) & $2.5(h)$ & $8.32(h)$ & $106.7(h)$ & $106.7(h)$ \\
\hline $\mathrm{t}_{\mathrm{m}}$ & 11.8 (min) & $12.0(\mathrm{~min})$ & $1.4(h)$ & $6.62(h)$ & $16.7(h)$ & $52.7(h)$ \\
\hline $\mathrm{u}_{\text {mean }}$ & 0.047 & 0.046 & 0.006 & 0.006 & 0.0012 & 0.00034 \\
\hline $\mathrm{u}_{\max }(\mathrm{m} / \mathrm{s})$ & 0.073 & 0.069 & 0.012 & 0.020 & 0.012 & 0.003 \\
\hline$\sigma^{2}\left(h^{2}\right)$ & 0.00191 & 0.00076 & 0.20 & 18.45 & 195.94 & 747.28 \\
\hline$\sigma_{\vartheta}^{2}(-)$ & 0.049 & 0.019 & 0.094 & 0.421 & 0.702 & 0.269 \\
\hline $\mathrm{D}_{\mathrm{x}}\left(\mathrm{m}^{2} / \mathrm{s}\right)$ & 0.038 & 0.014 & 0.009 & 0.199 & 0.024 & 0.003 \\
\hline$D_{x} / h u^{*}$ & 56 & 20 & 74 & 632 & 60 & 23 \\
\hline$D_{x} / W u^{*}$ & 1.8 & 0.6 & 0.6 & 7.9 & 9.6 & 3.7 \\
\hline $\operatorname{Re}(-)$ & 4640 & 5033 & 865 & 2177 & 2819 & 894 \\
\hline$D_{f}(-)$ & 0.37 & 0.34 & 0.50 & 0.69 & 0.91 & 0.90 \\
\hline$V_{e f f}\left(m^{3}\right)$ & 14.5 & 16.6 & 26.4 & 1670 & 902 & 2845 \\
\hline $\mathrm{M}_{\mathrm{o}}=\mathrm{t}_{90} / \mathrm{t}_{10}$ & 1.66 & 1.39 & 2.10 & 4.09 & 12.6 & 4.42 \\
\hline $\mathrm{Pe}$ & 40.7 & 105.7 & 21.3 & 4.75 & 2.8 & 7.4 \\
\hline $\mathrm{N}$ & 20.4 & 52.8 & 10.7 & 2.37 & 1.4 & 3.7 \\
\hline$B o=1 / P e$ & 0.025 & 0.009 & 0.05 & 0.21 & 0.35 & 0.13 \\
\hline $\mathrm{e}$ & 0.59 & 0.72 & 0.59 & 0.80 & 0.16 & 0.49 \\
\hline$\lambda$ & 0.85 & 0.96 & 0.80 & 0.55 & 0.13 & 0.66 \\
\hline
\end{tabular}

F. EM = Fully Emergent No Veg = Unplanted . 

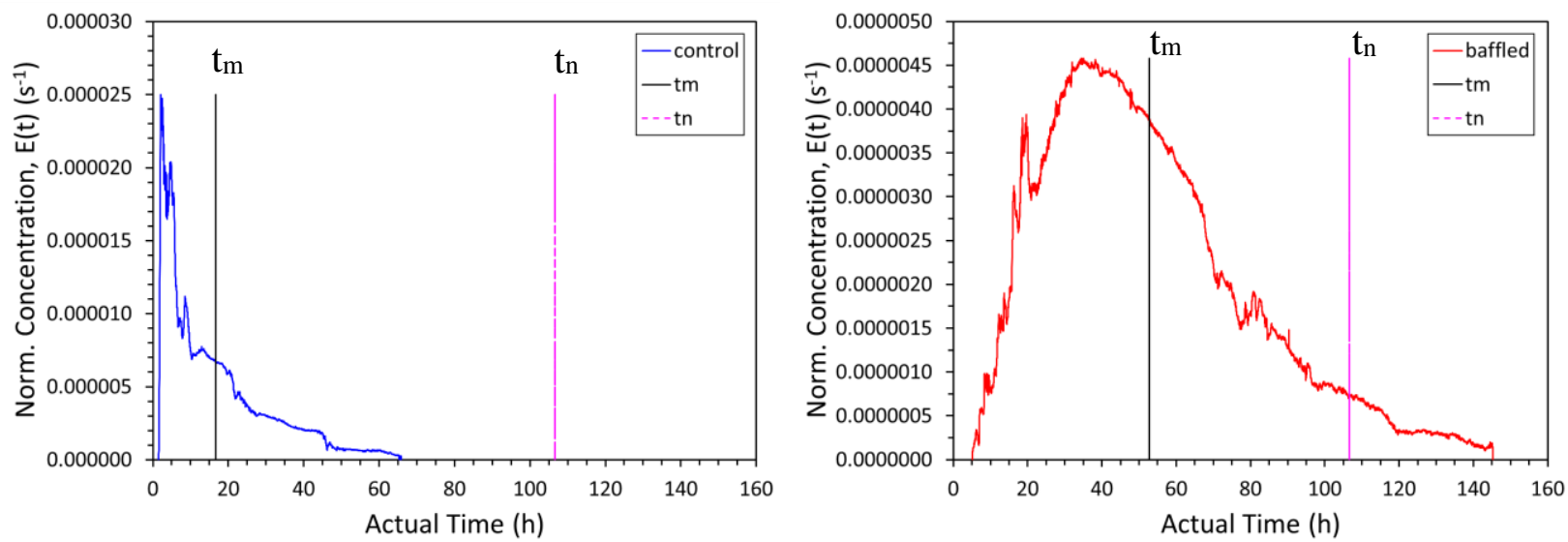

(a) Norm. RTD, Control Lagoon.

(b) Norm. RTD, Baffled Lagoon.
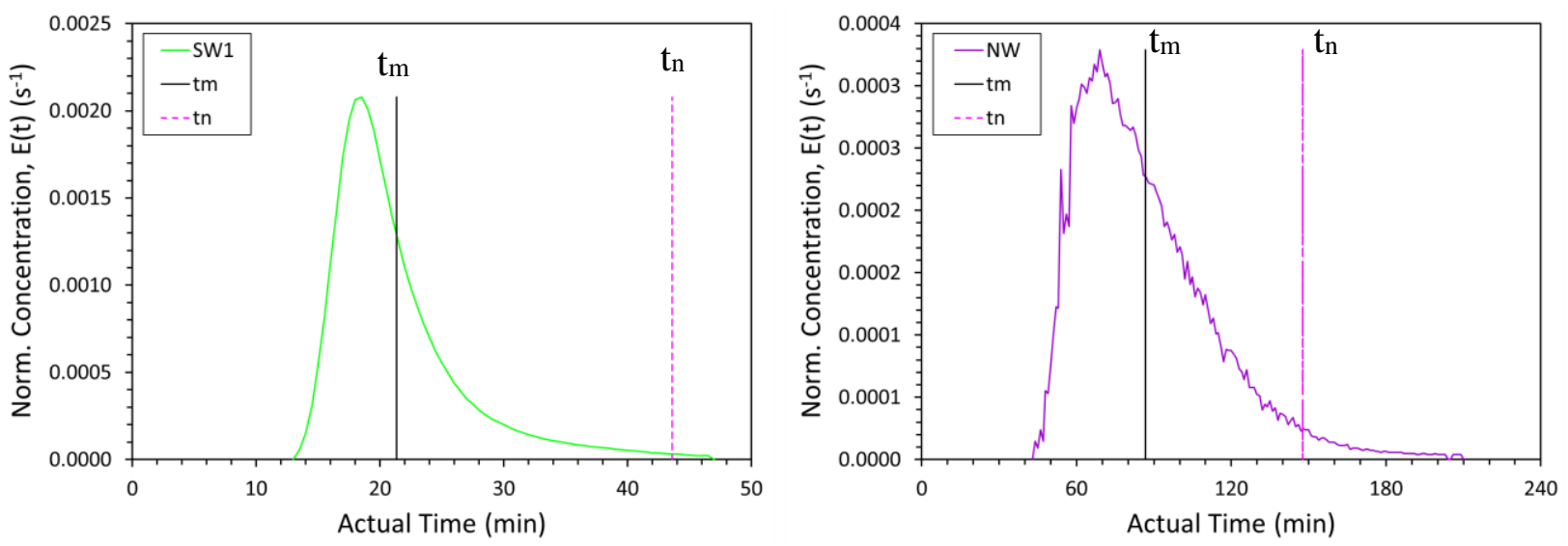

(c) Norm. RTD, SW1.

(d) Norm. RTD, NW.

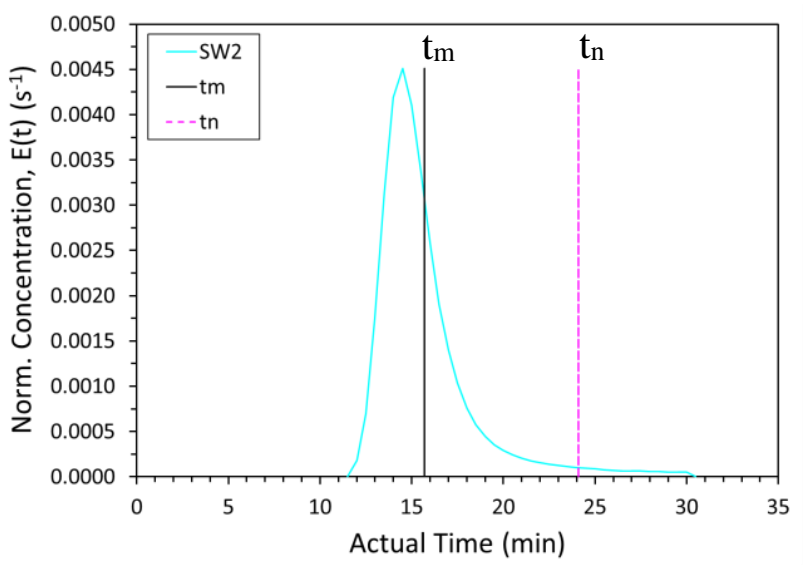

(e) Norm. RTD, SW2.

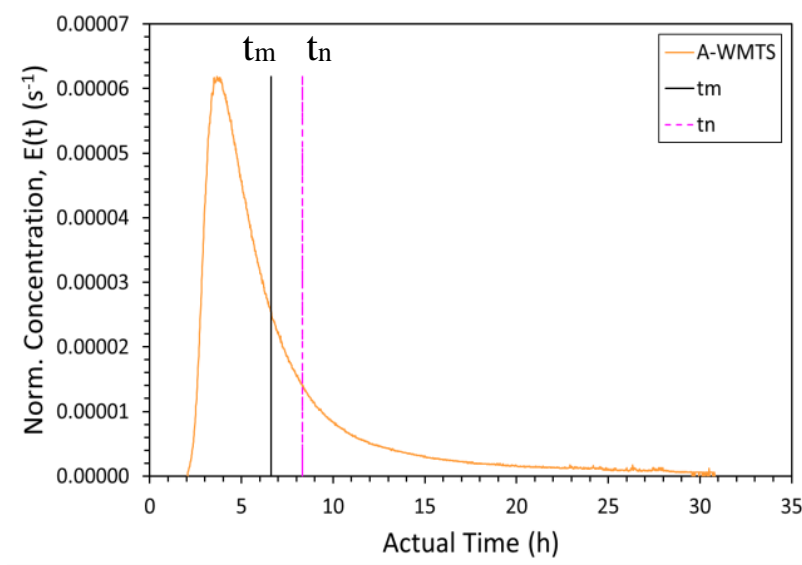

(f) Norm. RTD, A-WMTS.

Figure 5: Compiled RTD curves for each case study. 

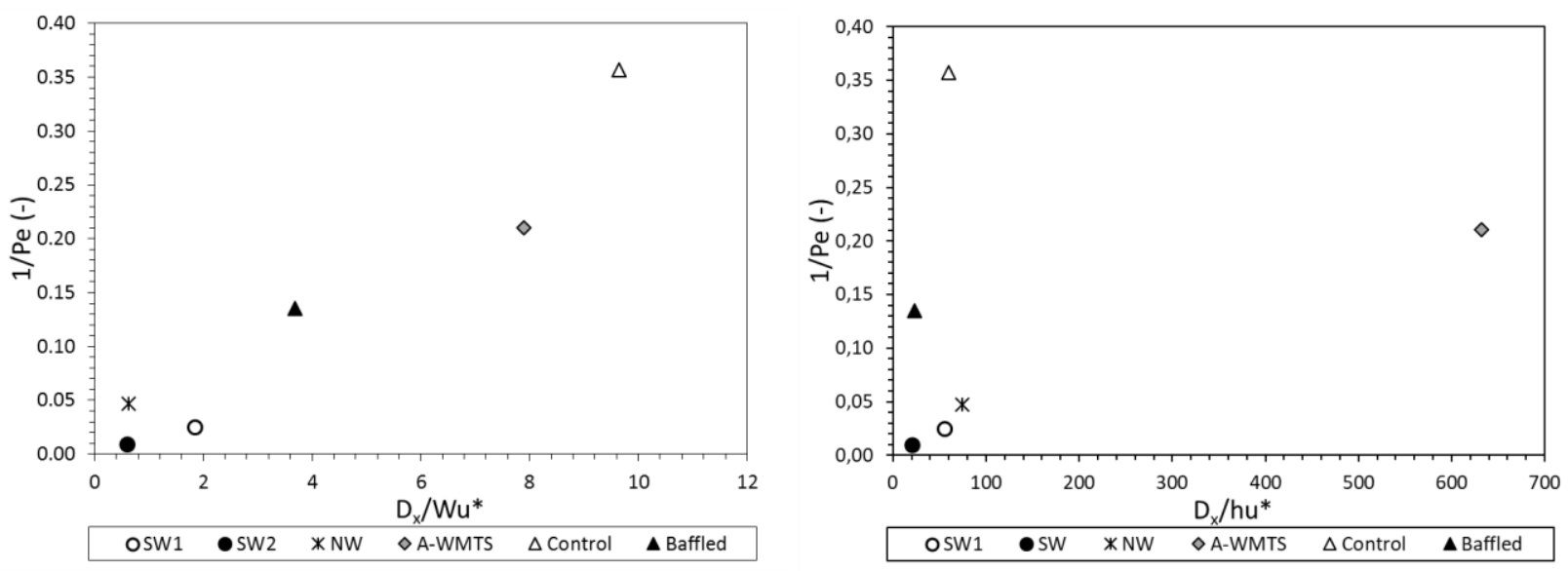

Figure 6: $1 / \mathrm{Pe}$ against $\mathrm{D}_{\mathbf{x}} / \mathrm{Wu}^{*}$ indicating zero scale effects between the systems. (Right) 1/Pe against $\mathrm{D}_{\mathbf{x}} / \mathrm{hu}^{*}$ indicating different scale effects between the systems. Width appears to be a more important dimension compared to depth in affecting mixing characteristics in different scale systems. 

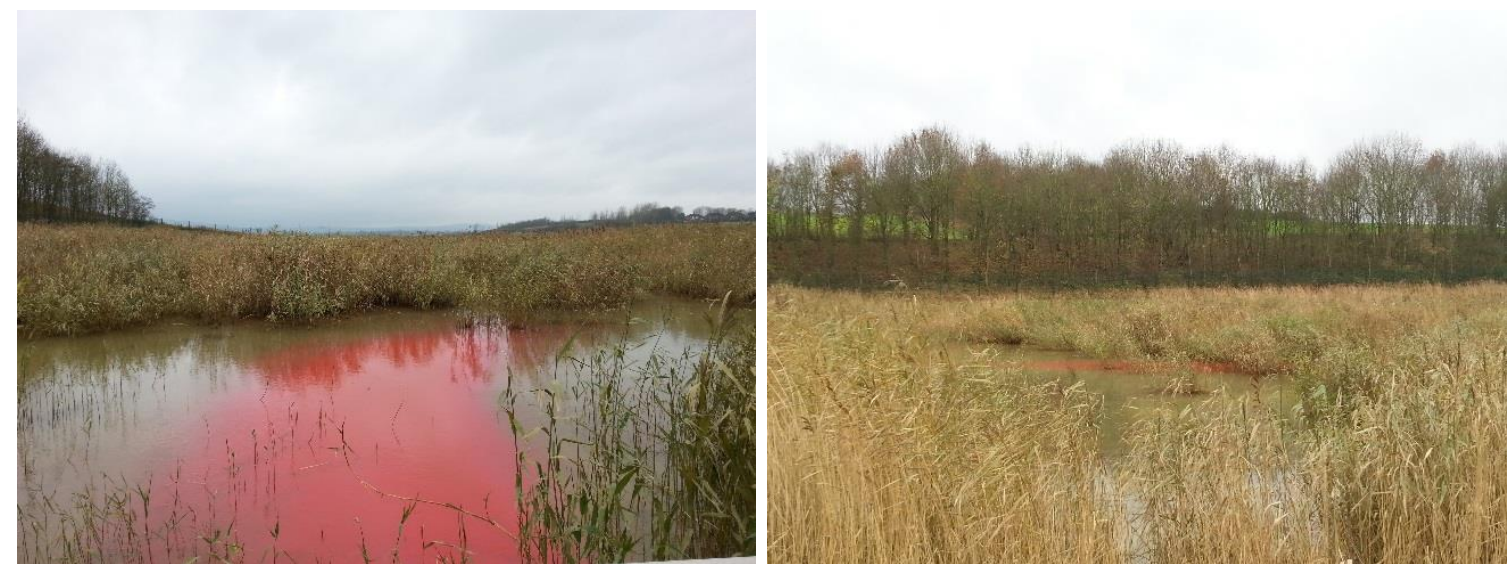

Figure 7: Tracer route during the normal inflow operational condition. Tracer takes an initial preferential path (Photo taken 3/12/15). 


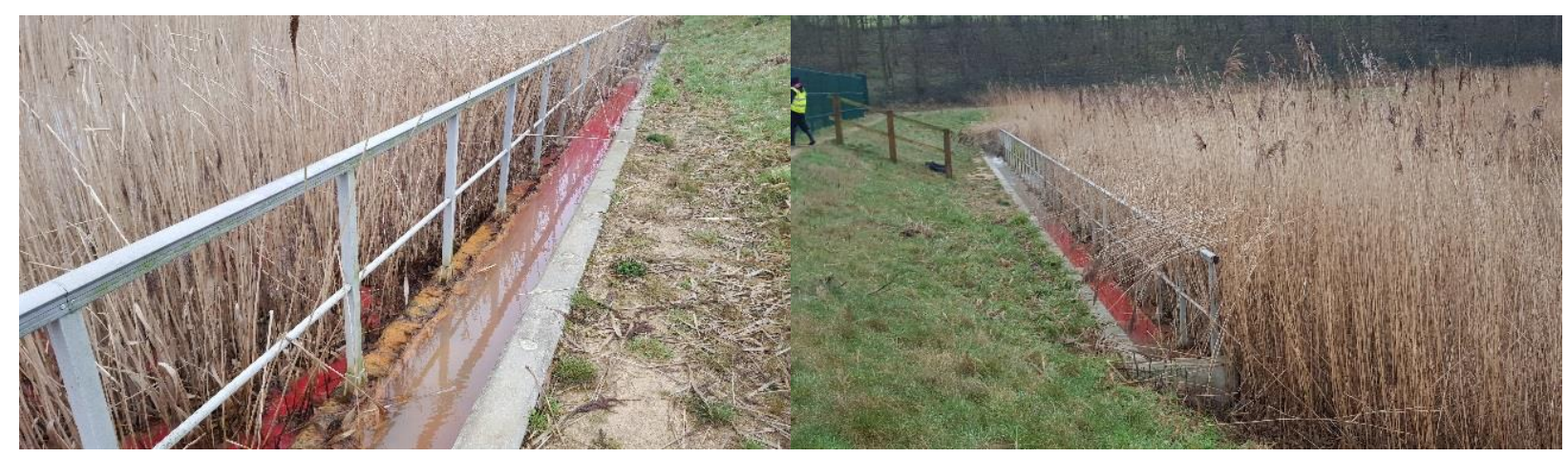

(a) Tracer forced at the low flow velocity area of the inlet weir.

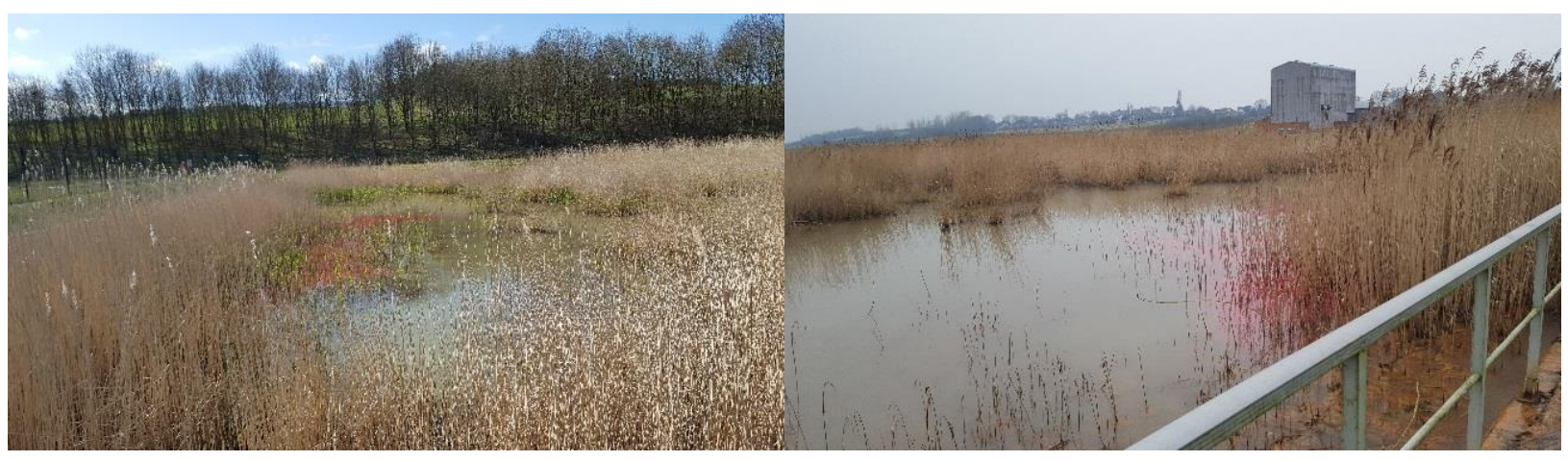

(b) Tracer follows a slow spread using the right side of the CW.

Figure 8: Tracer route during the single-lagoon inflow condition. Tracer is forced at the low flow velocity zone and spreads more slowly, following a different route (Photos taken 21/01/16). 


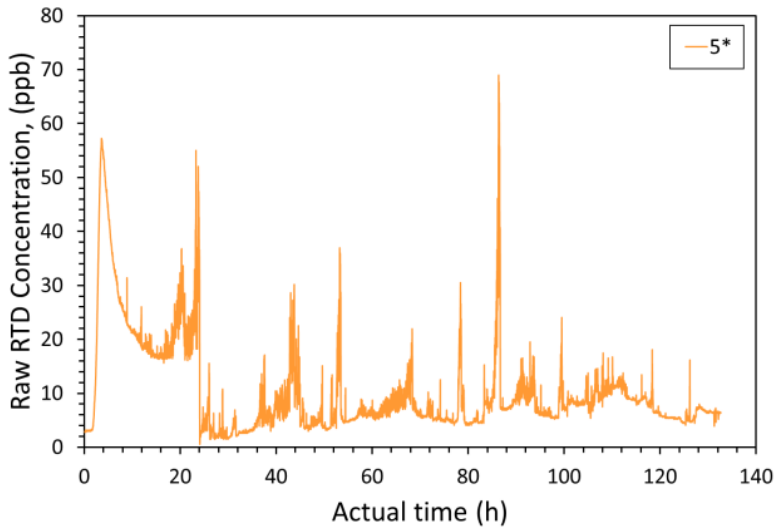

(a) April, recirculated currents.

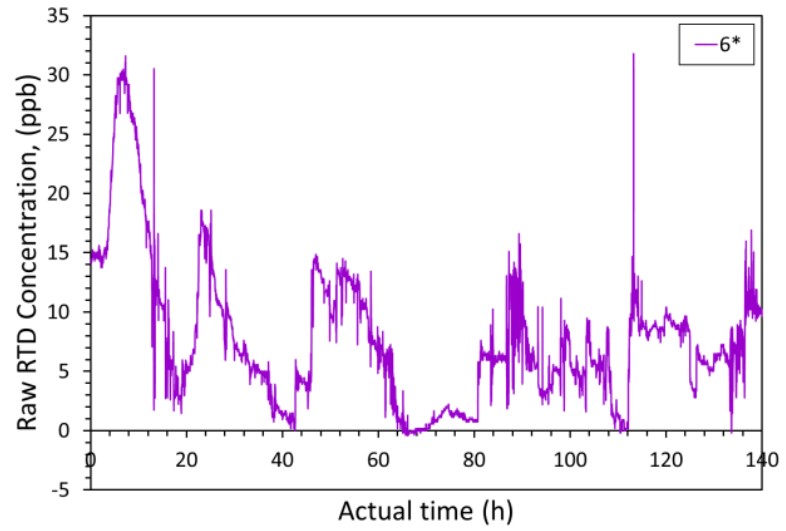

(b) May, promoted recirculation.

Figure 9: RTDs for post lagoon A breakdown period effects in A-WMTS. Fig. (a)-(b) indicate the recirculated currents promoted after the one inlet operation in April (a) and in May (b). 